\title{
Genetic Polymorphism of Glutathione $S$-transferase P1 and Breast Cancer Risk
}

\author{
Sook-Un Kim, Kyoung-Mu Lee, Sue-Kyung Park ${ }^{\dagger}$ Keun-Young Yoo, Dong-Young Noh, \\ Kook-Jin Choe", Sei-Hyun Ahns, Ari Hirvonen" and Daehee Kang* \\ Departments of Preventive Medicine and ${ }^{\ddagger}$ Surgery, Seoul National University College of Medicine, Cancer Research Institute, \\ 28 Yongon-Dong, Chongno-Gu, Seoul, 110-799, Korea \\ 'Department of Preventive Medicine, Konkuk University College of Medicine, Chungju, Chungcheongbuk-Do 390-701, Korea \\ ${ }^{\S}$ Department of Surgery, Asan Medical Center, Ulsan University College of Medicine, 388-1 Pungnab-Dong, Songpa-Gu, Seoul 138-736, Korea \\ "Department of Industrial Hygiene and Toxicology, Finnish Institute of Occupational Health, FIN-00250 Helsinki, Finland
}

Received 29 October 2003, Accepted 2 March 2004

To evaluate the potential association between the GSTP1 genotype and the development of breast cancer, a hospital based case-control study was conducted on Korean women. The study population consisted of 171 histologically confirmed incident breast cancer cases and 171 agematched controls with no present or previous history of cancer. PCR-RFLP was used for the GSTP1 genotyping and statistical evaluations were performed using an unconditional logistic regression model. Postmenopausal women with the GSTP1 Val allele were found to have a reduced risk of breast cancer $(\mathrm{OR}=0.3,95 \% \mathrm{CI}=0.10$ 0.74). A significant interaction was observed between the GSTP1 genotype and alcohol consumption ( $p$ for interaction $=0.01$ ) ; compared with never-drinking women with Ile/Ile genotype, ever-drinking women with the GSTP1 Val allele had almost a three-fold risk of breast cancer $(O R=\mathbf{2 . 9 , 9 5 \%}$ CI = 1.05 -7.85), whereas never-drinking women with Val allele had half this risk $(\mathrm{OR}=0.5,95 \% \mathrm{CI}=\mathbf{0 . 2 7}-\mathbf{0 . 9 3})$. Our findings suggest that the GSTP1 polymorphism influences individual susceptibility to breast cancer in the Korean women and this effect may be modified by alcohol consumption.

Keywords: Alcohol consumption, Breast cancer, Genetic polymorphism, GSTP1
*To whom correspondence should be addressed.

Tel: 82-2-740-8326; Fax: 82-2-747-4830

E-mail: dhkang@snu.ac.kr

\section{Introduction}

Breast cancer is the second most frequent cancer in Korean women, and its incidence is increasing (Yoo et al., 1998). The major risk factors of breast cancer are primarily related to reproductive events that influence lifetime estrogen exposure levels (Thompsen and Ambrosone, 2000). However, the carcinogenesis of breast cancer cannot be wholly explained by these factors, and in most cases, it is presumed to be related to environmental exposure (Lee, 2001). Thus, the identification of genetic susceptibility factors associated with the metabolism of environmental agents might provide further insight into the etiology of breast cancer (Smith et al., 1995).

Glutathione S-transferases (GSTs) are a superfamily of phase II enzymes that are involved in conjugating the reactive intermediates of endogenous and exogenous toxicants with soluble glutathione. Moreover, alterations in the structure, function, or expression of GST genes could alter the ability of a cell to inactivate carcinogens or mutagens, and thus modify an individual's risk. Our previous study suggested that the GSTM1 and GSTT1 genotypes are important modifiers of susceptibility to breast cancer among premenopausal Korean women (Park et al., 2000), and here we extended this study to evaluate the potential effects of GSTP1 Ile ${ }^{105} \mathrm{Val}$ polymorphism in this context.

Glutathione S-transferase P1 is a major GST, which is ubiquitously expressed in both normal and tumor breast tissue (Forrester et al., 1990; Shea et al., 1990; Albin et al., 1993), and the GSTP1 gene has been mapped to a small region of chromosome 11q. Recently polymorphisms in exon 5 $\left(\mathrm{Ile} \mathrm{C}^{105} \mathrm{Val}\right)$ and exon $6\left(\mathrm{Ala}{ }^{114} \mathrm{Val}\right)$ of the GSTPl gene were identified (Zimniak et al., 1994), and both affected codons lie in close proximity to the hydrophobic binding site of GSTP1. Moreover, the ${ }^{105} \mathrm{Val}$ variant has been demonstrated to have 
either lower or higher specific activity and affinity than that of ${ }^{105}$ Ile depending on the substrate (Ali-Osman et al., 1997; Sundberg et al., 1998), whereas the $A l a^{114} V a l$ polymorphism seems not to influence enzyme activity.

Previous epidemiological studies on the potential association between genetic polymorphisms of GSTP1 and breast cancer have produced inconsistent results (Hezlsouer et al., 1998; Millikan et al., 2000; Mitrunen et al., 2001; Gudnumdsdottir et al., 2001). These inconsistencies might be partly due to difference in population, and their exposures to factors of breast cancer development. We evaluated this issue for the first time in an Asian population.

\section{Materials and Methods}

Study subjects The study subjects consisted of a consecutive series of breast cancer patients and non-cancer controls admitted to three teaching hospitals located in Seoul, Korea (Seoul National University Hospital, Borame Hospital, and the Asan Medical Center), from March 1994 to September 1998. The study design and selection of study subjects have been described in detail elsewhere (Park et al., 2000). Women who were diagnosed as incident breast cancer cases with histopathological confirmation, and from whom a blood sample was available were selected as cases $(n=204)$. The controls $(n=332)$, who had no history of breast cancer, were recruited simultaneously at the same hospitals. Women with amenorrhea, a previous history of hysterectomy, oophorectomy, hormone replacement therapy, or hormone-related disease, such as thyroid problems were excluded. Those with benign breast tumor, other breast diseases (e.g., mastitis or a benign calcification), or other systemic problems like chronic liver diseases were also excluded from the controls. Using these criteria 189 cases and 233 controls were enrolled in the study. Each patient was then frequency-matched to control according to the following age groups: under 30, 30-34, 35$39,40-54,55-69$, and over 70 years. Consequently, the final study population consisted of 171 cases and 171 controls.

Informed consent was obtained at the time of blood withdrawal. Information on demographic characteristics, education, marital status, family history of breast cancer in first and second relatives, reproductive factors, menstruation, life styles including alcohol consumption, and diet were collected using a questionnaire administered by trained interviewers.

Genotyping DNA was isolated using standard methods from blood drawn into $10 \mathrm{ml}$ heparinized tubes and stored at $-70^{\circ} \mathrm{C}$ until use. The GSTP1 Ille ${ }^{105} \mathrm{Val}$ genotypes were determined by PCR-RFLP as described by Saarikoski et al. (1998). Briefly, a 173 bp fragment was amplified using the primers 5'-CAG TGA CTG TGT GTT GAT CA3' and 5'-TGC TCA CAT AGT TGG TGT AGA TGA GGG A(T)A3'. Subsequently, aliquots of the PCR products were digested using SnaB I restriction enzyme (New England Biolabs, Beverly, USA) and run on agarose gels. The presence of the SnaB I restriction site identified the presence of the GSTPI ${ }^{105} \mathrm{Val}$ allele and the absence of that restriction site identified the ${ }^{105} \mathrm{Ile}$ allele. To confirm the reliability of the assay, 50 randomly selected samples were re-tested and the identical results were obtained.
Statistical analyses Odds ratios (ORs) and 95\% confidence intervals (CIs) were calculated by unconditional logistic regression model. ORs were adjusted for age, education (at and over high school vs. under high school), body mass index, smoking, alcohol consumption, parity and age at the first full-term pregnancy (FFTP) (nullipara or FFTP $\geq 30 v s$. <29), duration of breast feeding, and a family history of breast cancer. Subjects who had smoked more than 400 cigarettes in their lifetime were defined as ever-smokers. The frequency of alcohol intake was categorized as never-drinkers, never or less than once per month, and ever drinkers, at least once per month.

The frequencies of the GSTPI Val/Val genotype were too small to evaluate the gene-dosage effect. Instead, the genotype data were divided into two groups (GSTP1 Ile/lle vs. Ile/Val or Val/Val) in the statistical analyses to increase statistical power. The possible geneenvironment interactions between the GSTP1 genotypes and other risk factors (e.g., body mass index, alcohol consumption, meat consumption, age at first full term pregnancy, and number of livebirth babies) on breast cancer development were evaluated using a likelihood ratio test.

\section{Results}

A higher education $(\mathrm{OR}=2.7,95 \% \mathrm{CI}=1.51-4.77)$, an older age at first full-term pregnancy $(\mathrm{OR}=3.2, \mathrm{CI}=1.60-6.52)$, two or more live-birth babies $(\mathrm{OR}=0.4,95 \% \mathrm{CI}=0.25-0.79)$, and alcohol consumption $(\mathrm{OR}=1.9,95 \% \mathrm{CI}=1.16-3.25)$ were found to be significantly associated with the risk of breast cancer.

The GSTP1 genotype distribution in control subjects was in agreement with those predicted by the Hardy-Weinberg equilibrium $(\mathrm{p}=1.00)$ (Table 1), and the frequency of GSTP1 Val allele containing genotypes in Korean women (34\%) was lower than that reported for Caucasians (45-60\%) (Hezlsouer et al., 1998; Millikan et al., 2000; Mitrunen et al., 2001; Gudnumdsdottir et al., 2001).

Although no association was found between GSTP1 Val allele containing genotypes and breast cancer risk for the total study population, a significantly reduced risk of breast cancer was observed in postmenopausal women $(\mathrm{OR}=0.3,95 \%$ $\mathrm{CI}=0.10-0.74)$ with these genotypes compared with women with GSTP1 Ile/Ile genotypes.

The GSTP1 Val allele showed a significant multiplicative interaction with alcohol consumption ( $p$ for interaction $=0.01$ ) (Table 2). Never-drinking women with the Val allele containing genotypes were found to have half the risk of never-drinking women with the GSTP1 Ile/Ile genotype $(\mathrm{OR}=0.5,95 \% \mathrm{CI}=0.27-0.93)$, and ever-drinking women with these genotypes were found to have almost a three-fold risk of developing breast cancer $(\mathrm{OR}=2.9,95 \% \mathrm{CI}=1.05$ 7.85). Therefore, the effect of alcohol consumption was only observed among those with the Val allele containing genotypes.

No significant interaction was observed between the GSTP1 genotypes and body mass index, meat consumption, age at first full-term pregnancy, or the number of live-births. 
Table 1. Association between GSTPl genotypes and breast cancer risk by menopausal status

\begin{tabular}{|c|c|c|c|c|c|c|c|c|c|}
\hline & \multicolumn{3}{|c|}{ All women } & \multicolumn{3}{|c|}{ Premenopausal women } & \multicolumn{3}{|c|}{ Postmenopausal women } \\
\hline & $\begin{array}{l}\text { Cases } \\
\mathrm{N}(\%)\end{array}$ & $\begin{array}{l}\text { Controls } \\
\mathrm{N}(\%)\end{array}$ & $\begin{array}{c}\text { OR } \\
(95 \% \mathrm{CI})^{\mathrm{a}}\end{array}$ & $\begin{array}{l}\text { Cases } \\
\mathrm{N}(\%)\end{array}$ & $\begin{array}{l}\text { Controls } \\
\text { N (\%) }\end{array}$ & $\begin{array}{c}\text { OR } \\
(95 \% \mathrm{CI})^{\mathrm{a}}\end{array}$ & $\begin{array}{l}\text { Cases } \\
\mathrm{N}(\%)\end{array}$ & $\begin{array}{c}\text { Controls } \\
\mathrm{N}(\%)\end{array}$ & $\begin{array}{c}\text { OR } \\
(95 \% \mathrm{CI})^{\mathrm{a}}\end{array}$ \\
\hline GSTP1 & & & & & & & & & \\
\hline Ile/Ile & $122(71.3)$ & $113(66.1)$ & 1.0 (reference) & $67(66.3)$ & $70(69.3)$ & 1.0 (reference) & 55 (78.6) & $43(61.4)$ & 1.0 (reference) \\
\hline Ile/Nal & $44(25.7)$ & $52(30.4)$ & $0.7(0.43-1.27)$ & $32(31.7)$ & $27(26.7)$ & $1.2(0.57-2.37)$ & $12(17.1)$ & $25(35.7)$ & $0.3(0.10-0.76)$ \\
\hline $\mathrm{Val} / \mathrm{Val}$ & $5(2.9)$ & $6(3.5)$ & $0.8(0.16-3.54)$ & $2(2.0)$ & $4(4.0)$ & $1.0(0.13-8.05)$ & $3(4.3)$ & $2(2.9)$ & $0.2(0.02-2.50)$ \\
\hline $\begin{array}{c}\text { Ile/Val or } \\
\text { Val/Val }\end{array}$ & 49 (28.7) & $58(33.9)$ & $0.7(0.44-1.25)$ & 34 (33.7) & $31(30.7)$ & $1.2(0.58-2.30)$ & $15(21.4)$ & 27 (38.6) & $0.3(0.10-0.74)$ \\
\hline
\end{tabular}

adjusted for age, education, body mass index, smoking, alcohol consumption, parity and age at first full term pregnancy, duration of breast feeding, and family history of breast cancer.

Table 2. OR and 95\% CIs for GSTP1 genotypes in relation to alcohol consumption $^{\mathrm{a}}$

\begin{tabular}{ccc}
\hline & $\begin{array}{c}\text { Ile/Ile } \\
\text { [cases/controls] }\end{array}$ & $\begin{array}{c}\text { Ile/Val or Val/Val } \\
\text { [cases/controls] }\end{array}$ \\
\hline Alcohol consumption & & \\
$<1 /$ month & 1.0 (reference) & $0.5(0.27-0.93)$ \\
& {$[91 / 90]$} & {$[30 / 51]$} \\
$\geq 1$ month & $1.2(0.56-2.37)$ & $2.9(1.05-7.85)^{\mathrm{b}}$ \\
& {$[31 / 23]$} & {$[19 / 7]$} \\
\hline
\end{tabular}

adjusted for age, education, body mass index, parity and age at first full term pregnancy, duration of breast feeding, family history of breast cancer and menopausal status.

${ }^{\mathrm{b}} \mathrm{p}$ for interaction $=0.01$.

\section{Discussion}

No significant overall association has been reported between the GSTP1 Ile ${ }^{105} \mathrm{Val}$ polymorphism in breast cancer in previous studies (Harries et al., 1997; Hezlsouer et al., 1998; Curran et al., 2000; Millikan et al., 2000; Gudnumdsdottir et al., 2001; Krajinovic et al., 2001; Mitrunen et al., 2001). Our finding that the GSTP1 Val allele has a slight protective effect against breast cancer agrees with the findings of Millikan et al. (2000), and Mitrunen et al. (2001), but disagrees with the findings of Helzlsouer et al. (1998) and Gudmundsdottir et al. (2001), which found that the GSTP1 Val allele had the opposite overall effect. Inconsistent results might be that the enzyme encoded by GSTP1 Val allele exhibit different activity, affinity, and thermostability according to substrates. For example, a recent fundamental study reported that the GSTP1 Val variant showed lower catalytic activity for 1chloro-2,4-dinitrobenzene (CDNB), but higher activity for 4vinylpyridine and (+)-antibenzo[a]pyrene-diol-epoxide (BPDE) (Coles et al., 2000).

The most interesting finding of the present study is the potential interaction between GSTP1 genotypes and alcohol consumption. The biologic mechanisms underlying this interaction remain unclear; however, in some cases, glutathione conjugation can result in chemical intermediates that are more reactive than the parent compounds (Andres et al., 1998). Therefore, it is possible that more reactive intermediate metabolites are generated by the GSTP1 Val variant during alcohol metabolism. However this issue remains to be further explored.

To conclude, although our study has several limitations, i.e., the moderate sample size and the use of hospital controls, it is the first epidemiological evaluation of the relationship between GSTP1 polymorphism and breast cancer in Asian women. Our results also suggest for the first time that the GSTP1 Ile ${ }^{105} \mathrm{Val}$ polymorphism may influence the alcohol consumption associated individual susceptibility to breast cancer.

Acknowledgments This study was supported by grant (2003-022) from the Asan Institute for Life Sciences, Seoul, Korea.

\section{References}

Albin, N., Massaad, L., Toussaint, C., Mathieu, M. C., Morizet, J., Parise, O., Gouyette, A. and Chabot, G. G. (1993) Main drugmetabolizing enzyme systems in human breast tumors and peritumoral tissues. Cancer Res. 53, 3541-3546.

Ali-Osman, F., Akande, O., Antoun, G., Mao, J. X. and Buolamwini, J. (1997) Molecular cloning, characterization, and expression in Escherichia coli of full-length cDNAs of three human glutathione S-transferase Pi gene variants. Evidence for differential catalytic activity of the encoded proteins. J. Biol. Chem. 272, 10004-10012.

Andres, M. W. and Dekant, W. (1998) Glutathione-dependent bioactivation of haloalkanes. Annu. Rev. Pharmacol. Toxicol. 38, 501-537.

Coles, B., Yang, M., Lang, N. P. and Kadlubar, F. F. (2000) Expression of hGSTP1 alleles in human lung and catalytic activity of the native protein variants towards 1-chloro-2,4dinitrobenzene, 4-vinylpyridine and (+)-anti benzo[a]pyrene-7,8diol-9,10-oxide. Cancer Lett. 156, 167-175.

Curran, J. E., Weinstein, S. R. and Griffiths, L. R. (2000) 
Polymorphisms of glutathione S-transferase genes (GSTM1, GSTP1 and GSTTI) and breast cancer susceptibility. Cancer Lett. 153, 113-120.

Forrester, L. M., Hayes, J. D., Millis, R., Barnes, D., Harris, A. L., Schlager, J. J., Powis, G. and Wolf, C. R. (1990) Expression of glutathione S-transferases and cytochrome P450 in normal and tumor breast tissue. Carcinogenesis 11, 21632170 .

Gudmundsdottir, K., Tryggvadottir, L. and Eyfjord, J. E. (2001) GSTM1, GSTT1, and GSTP1 genotypes in relation to breast cancer risk and frequency of mutations in the p53 gene. Cancer Epidemiol. Biomark. Prev. 10, 1169-1173.

Harries, L. W., Stubbins, M. J., Forman, D., Howard, G. C. and Wolf, C. R. (1997) Identification of genetic polymorphisms at the glutathione S-transferase $\mathrm{Pi}$ locus and association with susceptibility to bladder, testicular and prostate cancer. Carcinogenesis 18, 641-644.

Helzlsouer, K. J., Selmin, O., Huang, H. Y., Strickland, P. T., Hoffman, S., Alberg, A. J., Watson, M., Comstock, G. W. and Bell, D. (1998) Association between glutathione S-transferase M1, P1, and T1 genetic polymorphisms and development of breast cancer. J. Natl. Cancer. Inst. 90, 513-518.

Kang, D. (2003) Genetic polymorphisms and cancer susceptibility of breast cancer in Korean women. J. Biochem. Mol. Biol. 36(1), 28-34.

Krajinovic, M., Ghadirian, P., Richer, C., Sinnett, H., Gandini, S., Perret, C., Lacroixi, A., Labuda, D. and Sinnett, D. (2001) Genetic susceptibility to breast cancer in French-Canadians: role of carcinogen-metabolizing enzymes and gene-environment interactions. Int. J. Cancer 92, 220-225.

Lee, S. H. (2001) Recognition of DNA damage in mammals. $J$. Biochem. Mol. Biol. 34, 489-495.

Millikan, R., Pittman, G., Tse, C., Savitz, D. A., Newman, B. and Bell, D. (2000) Glutathione S-transferase M1, T1, and P1 and breast cancer. Cancer Epidemiol. Biomark. Prev. 9, 567-573.

Mitrunen, K., Jourenkova, N., Kataja, V., Eskelinen, M., Kosma, V. M., Benhamou, S., Vainio, H., Uusitupa, M. and Hirvonen, A. (2001) Glutathione S-transferase M1, M3, P1, and T1 genetic polymorphisms and susceptibility to breast cancer. Cancer Epidemiol. Biomark. Prev. 10, 229-236.

Park, S. K., Yoo, K. Y., Lee, S. J., Kim, S. U., Ahn, S. H., Noh, D. Y., Choe, K. J., Strickland, P. T., Hirvonen, A. and Kang, D. H. (2000) Alcohol consumption, glutathione S-transferase $\mathrm{M} 1$ and $\mathrm{T} 1$ genetic polymorphisms and breast cancer risk. Pharmacogenetics 10, 301-309.

Saarikoski, S. T., Voho, A., Reinkainen, M., Anttlia, S., Karjalainen, A., Malaveille, C., Vaino, H., HusgafvelPursiainen, K. and Hirvonen, A. (1998) Combined effect of polymorphic GST genes on individual susceptibility to lung cancer. Int. J. Cancer 77, 516-521.

Shea, T. C., Claflin, G., Comstock, K. E., Sanderson, B. J., Burstein, N. A., Keenan, E. J., Mannervik, B. and Henner, W. D. (1990) Glutathione transferase activity and isoenzyme composition in primary human breast cancers. Cancer Res. 50, 6848-6853.

Smith, G., Stanley, L. A., Sim, E., Strange, R. C. and Wolf, C. R. (1995) Metabolic polymorphisms and cancer susceptibility. Cancer Surv. 25, 27-65.

Sundberg, K., Johansson, A. S., Stenberg, G., Widersten, M., Seidel, A., Mannervik, B. and Jernstrom, B. (1998) Differences in the catalytic efficiencies of allelic variants of glutathione transferase P1-1 towards carcinogenic diol epoxides of polycyclic aromatic hydrocarbons. Carcinogenesis 19, 433-436.

Thompsen, P. A. and Ambrosone, C. (2000) Molecular epidemiology of genetic polymorphisms in estrogen metabolizing enzymes in human breast cancer. J. Natl. Cancer Inst. Monogr. 27, 125-134.

Yoo, K. Y., Park, S. K., Sung, J. H., Kang, D. H., Kim, Y. C., Kang, H. S., Suh, J. S., Kim, J. S., Yun, I. J., Han, S. H., Noh, D. Y. and Choe, K. J. (1998) High risk groups for female breast cancer in Korea. J. Korean Cancer Ass. 30, 435-439.

Zimniak, P., Nandur, B., Pikula, S., Bandorowics-Pinkula, J., Singhal, S., Srivastava, S., Awashthi, S. and Awashthi, Y. (1994) Naturally occurring human glutathione S-transferase GSTP1-1 isoforms with isoleucine and valine in position 105 differ in enzymatic properties. Eur. J. Biochem. 224, 893-899. 